\title{
Expression of COX-2 and steroid converting enzymes in breast cancer
}

\author{
CECILIA GUNNARSSON ${ }^{1}$, AGNETA JANSSON ${ }^{1}$, BIRGITTA HOLMLUND ${ }^{1}$, LILIANNE FERRAUD ${ }^{1}$, \\ BO NORDENSKJÖLD ${ }^{1}$, LARS ERIK RUTQVIST ${ }^{2}$, LAMBERT SKOOG ${ }^{3}$ and OLLE STÅL ${ }^{1}$ \\ ${ }^{1}$ Division of Oncology, Department of Biomedicine and Surgery, Faculty of Health Sciences, \\ Linköping University, SE-581 85 Linköping; ${ }^{2}$ Clinic of Oncology and ${ }^{3}$ Division of Cytology, \\ Karolinska University Hospital, SE-104 01 Stockholm, Sweden
}

Received February 6, 2006; Accepted April 4, 2006

\begin{abstract}
COX-2 is upregulated in many breast tumors, and one of the products of COX-2 is PGE2 that is suggested to upregulate aromatase through cAMP signaling in breast cancer. Although aromatase can increase the estrogen levels in tumors, 17ß-hydroxysteroid dehydrogenase (17HSD) activity is finally needed for the estrone/estradiol regulation. The aim of this study was to investigate if the protein expression of enzymes involved in estrogen synthesis shows covariation with the expression of COX-2. We also wanted to correlate these results with prognosis. We analyzed the expression of COX-2, aromatase, 17HSD1 and 17HSD2 with immunohistochemistry using tissue microarrays composed of 356 primary breast tumors. In the present study COX-2 was correlated to aromatase $(\mathrm{P}<0.00001)$, 17HSD1 $(\mathrm{P}=0.0073)$, and 17HSD2 $(\mathrm{P}<0.00001)$. Patients with ER positive tumors expressing low amounts of 17HSD2 had decreased breast cancer survival $(\mathrm{P}=0.013)$. Elevated expression of $\mathrm{COX}-2$ and aromatase was more frequent among larger tumors $(\mathrm{P}=0.017$ and $\mathrm{P}=0.013)$. COX-2 expression correlates with the levels of the examined steroid converting enzymes and may contribute to increased estrogen levels in the tumor. In breast cancer cells, the regulatory function of 17HSD2 could be lost, and in the present study patients with low or non-detectable levels of 17HSD2 had worse prognosis than had breast cancer patients with higher levels of the enzyme.
\end{abstract}

\section{Introduction}

In addition to the role of cyclooxygenase-2 (COX-2) in acute inflammation, recent work suggests that COX-2 derived metabolites are important during tumorigenesis such as pre-

Correspondence to: Dr Cecilia Gunnarsson, Department of Oncology, University Hospital, SE-581 85 Linköping, Sweden E-mail: cecilia.gunnarsson@lio.se

Key words: 17ß-hydroxysteroid dehydrogenase, COX-2, aromatase, breast cancer malignant proliferation, maintenance of tumor viability, growth, invasion and metastatic spread. Overexpression of COX-2 has been demonstrated in different human malignancies such as colon (1), lung (2), prostate (3), pancreas (4) and breast cancer (5). Several studies have demonstrated an enhanced expression of COX-2 mRNA and protein expression in breast carcinomas $(6,7)$. Some studies reported a correlation between COX-2 expression and prognosis $(8,9)$, whereas others did not find this association (10). The cyclooxygenases (COX-1 and COX-2) are responsible for the conversion of arachidonic acid to prostaglandins. COX-1 is constitutively expressed in most tissues and is responsible for maintaining psysiological processes. In contrast, COX-2 is induced by a wide spectrum of growth factors, oncogenes and cytokines in response to inflammation or neoplasia. A positive correlation between aromatase and COX-2 expression in breast cancer has been observed $(11,12)$.

Estrogen is mitogenic to the breast and plays an important role in the growth of hormone-dependent breast cancer. The source of estradiol differs between pre- and postmenopausal women. Before menopause, the majority of estradiol is synthesized by the ovaries, and among postmenopausal women the cessation of ovarian estradiol production leads to a decrease in plasma estradiol levels. However, the levels of estradiol in human breast tumors among postmenopausal women are much higher than the estradiol level in plasma (13). The mechanisms responsible for maintenance of high estradiol concentrations are not completely defined but are likely to involve local production of estradiol by the tumor itself. Androstenedione, produced primarily by the adrenals, is converted to estrone by aromatase in extra glandular tissue. Estrone can also be conjugated by sulfatase into estrone sulfate to form a slowly turning over storage pool, with a potential for back conversion to estrone. Levels of the sulfatase enzyme are actually higher in breast tumors than the levels of aromatase, however, the affinity for the substrate is lower.

Even if aromatase can increase the estrone level in breast tumors, 17ß-hydroxysteroid dehydrogenase (17HSD) activity is finally needed for the estradiol/estrone regulation. The 17HSD1 enzyme uses NADPH as a cofactor and catalyzes the interconversion of the weak estrogen, estrone (E1), to the biologically more potent estradiol (E2). 17HSD2 uses NAD ${ }^{+}$ 
COX-2

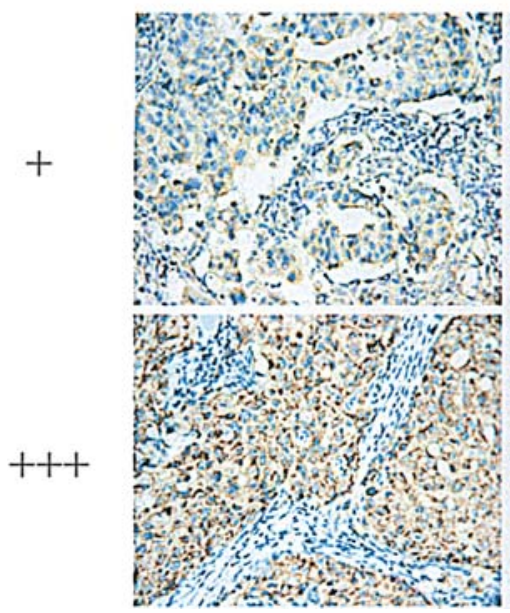

Aromatase

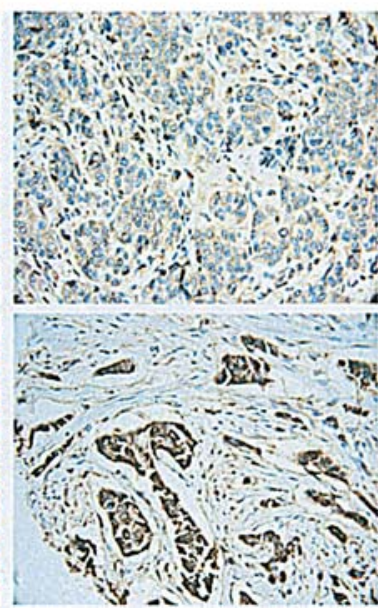

17HSD1

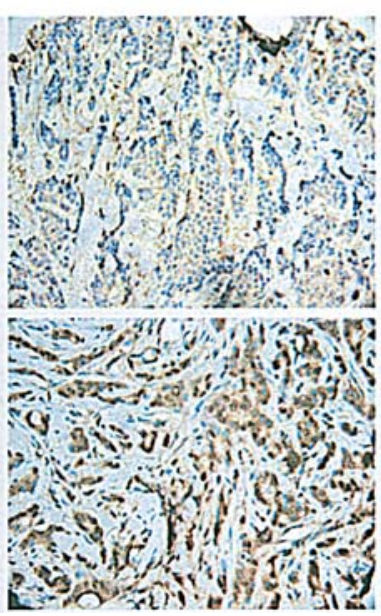

17HSD2

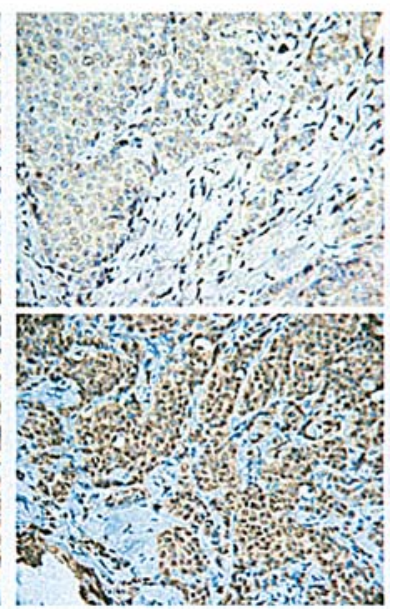

Figure 1. The immunostaining of COX-2, aromatase, 17HSD1, and 17HSD2 was scored as negative (-), weak (+), moderate (++), and strong (+++). Examples of tumors exhibiting weak and strong staining, respectively, are shown.

as a cofactor and catalyzes the oxidation of testosterone and estradiol to form androstendione and estrone, respectively (14). Previous studies have reported on the presence of multiple members of the 17HSD-family in human breast tumors, including types 3, 4 and 5 (15), although types 1 and 2 seem to be the principal enzymes involved in reductive and oxidative activity in breast cancer, respectively (16). In previous studies we have found that the expression of both 17HSD1 and 17HSD2 may have prognostic importance in breast cancer $(17,18)$.

The aim of this study was to investigate if the expression of enzymes involved in estrogen synthesis shows association with the expression of COX-2 in breast tumors. We also correlated these results to prognosis.

\section{Materials and methods}

Patients. The patient series consisted of 356 breast cancer cases treated in Stockholm, Sweden, in 1977-1990. All patients had primary breast cancer and were postmenopausal at the time of diagnosis. All patients were lymph node negative and had a tumor diameter $\leq 30 \mathrm{~mm}$. After surgery the patients were randomized to tamoxifen treatment or no endocrine treatment. The median follow-up time was 17 years. The study was approved by the regional ethics committee at Karolinska Institute.

Breast cancer tissue microarray (TMA). Representative tissue blocks were selected as donor blocks for the TMA. Sections were cut from each donor block and stained with hematoxylin and eosin. From these slides three morphologically representative regions were chosen (when possible) in each of the 356 tumor samples. Three cylindrical core tissue specimens (diameter $0.8 \mathrm{~mm}$ ) were taken from these areas in each case and mounted in a recipient block, with a total amount at most of 243 cores/block. The tissue microarrays were constructed using a manual arrayer (Beecher Inc., WI,
USA). Six tissue array blocks were prepared, each containing 66-243 tumor sample cores. Liver samples were included on each tissue block as a control.

Immunostaining for $\mathrm{COX}-2$, aromatase, 17HSD1 and 2 protein expression. TMA blocks were cut with a microtome into 4- $\mu \mathrm{m}$ sections and mounted on frost coated glass slides. The TMA sections were deparaffinized in xylene, rehydrated and thereafter rinsed in distilled water. Antigen retrieval was performed by placing the slides in an oven $\left(78^{\circ} \mathrm{C}\right)$ in citrate buffer $(\mathrm{pH} 6.0)$ for $20 \mathrm{~h}$. The slides were incubated in $3 \% \mathrm{H}_{2} \mathrm{O}_{2} /$ methanol for $15 \mathrm{~min}$ to block the endogenous peroxidase activity. Thereafter, the sections were incubated with the COX-2 monoclonal antibody (160112; Cayman Chemicals Co., Ann Arbor, MI) in 1:250 dilution for $24 \mathrm{~h}$ at $4^{\circ} \mathrm{C}$, followed by incubation with a secondary antibody complex, EnVision HRP, anti-mouse (Dako, Denmark) for $25 \mathrm{~min}$. After that, 3,3-diaminobenzidine tetrahydrochloride (DAB) $/ \mathrm{H}_{2} \mathrm{O}_{2}$ was used for $8 \mathrm{~min}$ to visualize the immunoreaction, and finally the slides were counterstained with hematoxylin, dehydrated and mounted. The immunostaining procedure with antibodies against aromatase (Nordic Biosite AB, Täby, Sweden), 17HSD1 and 17HSD2 (a kind gift from Professor F. Labrie and Professor V. Luu-The, Quebec, Canada) followed the same protocol as that for COX-2 immunostaining. However, these were all polyclonal (secondary antibody; Envision HRP anti-rabbit, Dako) and the dilutions were: aromatase 1:400, 17HSD1 1:2500, and 17HSD2 1:2000. Out of 356 tumors, approximately 19\% were either detached during the preparation of the specimens or did not contain a sufficient number of tumor cells.

Evaluation of immunohistochemical staining. The slides were evaluated independently by two investigators (CG and OS) without knowledge of clinicopathological information. The intensity was classified as negative, weak, moderate or strong in tumor cells. In cases with different scoring results, a consensus score was reached after re-evaluation. In some 
Table I. Correlation between COX-2, aromatase, 17HSD1 and 17HSD2 protein expression.

\begin{tabular}{|c|c|c|c|c|c|c|}
\hline & \multicolumn{2}{|c|}{ Aromatase } & \multicolumn{2}{|c|}{ 17HSD1 } & \multicolumn{2}{|c|}{ 17HSD2 } \\
\hline & n $(\%)$ & $\begin{array}{c}+ \\
\mathrm{n}(\%)\end{array}$ & $\mathrm{n}(\%)$ & $\begin{array}{c}+ \\
\mathrm{n}(\%)\end{array}$ & n $(\%)$ & $\begin{array}{c}+ \\
\mathrm{n}(\%)\end{array}$ \\
\hline \multicolumn{7}{|c|}{ COX-2 } \\
\hline- & $98(63)$ & $57(37)$ & $83(56)$ & $64(44)$ & $104(66)$ & $53(34)$ \\
\hline \multirow[t]{2}{*}{+} & $42(41)$ & $60(59)$ & $42(44)$ & $53(56)$ & $46(48)$ & $50(52)$ \\
\hline & & $\mathrm{P}=0.00052$ & & $\mathrm{P}=0.063$ & & $\mathrm{P}=0.004$ \\
\hline \multicolumn{7}{|c|}{ Aromatase } \\
\hline- & & & $85(65)$ & $45(35)$ & $95(71)$ & $38(29)$ \\
\hline \multirow[t]{2}{*}{+} & & & $38(36)$ & $67(64)$ & $45(41)$ & $65(59)$ \\
\hline & & & & $\mathrm{P}=0.00001$ & & $\mathrm{P}<0.00001$ \\
\hline \multicolumn{7}{|c|}{ 17HSD1 } \\
\hline- & & & & & $81(68)$ & $39(32)$ \\
\hline \multirow[t]{2}{*}{+} & & & & & $52(46)$ & $61(54)$ \\
\hline & & & & & & $\mathrm{P}=0.0093$ \\
\hline
\end{tabular}

statistical analysis, negative and weak cases were considered as a group with low expression levels, and cases with moderate and strong staining as a group with high levels.

\section{Results}

Association of COX-2 staining with aromatase, 17HSD1 and 17HSD2 staining. Immunoreactivity of COX-2 was evaluated in 284 breast carcinomas, of which $17.5 \%$ showed negative, $44.5 \%$ weak, $28 \%$ moderate and $10 \%$ strong staining. COX-2 immunoreactivity was localized exclusively to the cytoplasm of the tumor cells, whereas the stroma was negative. Expression of aromatase was successfully evaluated in 270 breast carcinomas, of which $9 \%$ showed negative, $47 \%$ weak, $38 \%$ moderate and $6 \%$ strong staining. Aromatase immunoreactivity was localized to the cytoplasm and in some cases to the stroma surrounding the tumor cells.

In 253 tumors the protein expression of 17HSD1 was assessable. The expression of 17HSD1 was negative in $8 \%$, weak in $44 \%$, moderate in $39.5 \%$ and strong in $8.5 \%$. The immunoreactivity of 17HSD1 was predominantly observed in the cytoplasm. Among the 265 tumors analyzed, the 17HSD2 protein expression was negative in $16 \%$, weak in $42.5 \%$, moderate in $36 \%$, and strong in $5.5 \%$. 17HSD2 immunoreactivity was localized to the cytoplasm of the tumor cells, and the surrounding stroma was negative. Examples of weak and strong immunostaining for the different proteins are shown in Fig. 1.

When divided into four groups, COX-2 protein expression correlated to aromatase $(\mathrm{P}<0.00001), 17 \mathrm{HSD} 1 \quad \mathrm{P}=0.0073)$ and 17HSD2 $(\mathrm{P}<0.00001)$. In the subsequent analysis the expression levels were divided into two groups, high/+ (scores moderate/strong) or low/- (scores negative/weak) (Table I). The expression of aromatase correlated significantly with 17HSD1 $(\mathrm{P}=0.00001)$ and 17HSD2 $(\mathrm{P}<0.00001)$.

Associations with clinicopathological data. Elevated expression of COX-2 was significantly more frequent among larger tumors
$(\mathrm{P}=0.017)$. No significant association was found between $\mathrm{COX}-2$ protein expression and estrogen receptor (ER) status. Moreover, high aromatase expression was associated with large tumors $(\mathrm{P}=0.013)$, but no association was found between aromatase and ER-status (Table II).

Prognostic value of COX-2, aromatase, 17HSD1 and 17HSD2. The prognostic importance for the different enzymes was investigated among ER-positive patients. There was no significant difference in distant recurrence-free survival or breast cancer related survival between patients with COX-2 positive and COX-2 negative breast carcinomas (Table III). No prognostic difference was seen among patients with different expression for aromatase or 17HSD1. However, patients with ER positive breast tumors with low levels of 17HSD2 had a worse prognosis, both concerning distant recurrence $(\mathrm{P}=0.055)$ and breast cancer related death $(\mathrm{P}=0.013)$. Kaplan-Meier curves for distant recurrence-free survival and breast cancer related survival are depicted in Fig. 2. The prognostic value for 17HSD2 remained significant in a multivariate analysis with regard to breast cancer specific survival (Table IV). Among ER negative patients no significant prognostic value was detected with different expression levels of the enzymes.

\section{Discussion}

In the present study COX-2 correlated to aromatase as well as to 17HSD1 and 17HSD2. The significant association between COX-2 and aromatase is in line with earlier studies. Brodie et al (11) showed a strong positive correlation between aromatase and COX-2 expression in breast cancer, and Brueggemeier et al (12) have shown a strong association between mRNA levels of COX-2 and aromatase (12). In breast tumors the regulation of aromatase expression is associated with a switch in the promoter region utilized in gene expression. PGE2 (as a result of COX-2 activity) is a known stimulant of cAMP in breast cancer cells, and is suggested to be important in the switching of aromatase promoters (19). If these mechanisms 
Table II. Expression of COX-2, aromatase, 17HSD1 and 17HSD2 in relation to other characteristics.

\begin{tabular}{|c|c|c|c|c|c|c|c|c|}
\hline & \multicolumn{2}{|c|}{ COX-2 } & \multicolumn{2}{|c|}{ Aromatase } & \multicolumn{2}{|c|}{ 17HSD1 } & \multicolumn{2}{|c|}{ 17HSD2 } \\
\hline & n $(\%)$ & $\begin{array}{c}+ \\
\mathrm{n}(\%)\end{array}$ & $\mathrm{n}(\%)$ & $\begin{array}{c}+ \\
\mathrm{n}(\%)\end{array}$ & n $(\%)$ & $\begin{array}{c}+ \\
\mathrm{n}(\%)\end{array}$ & $\mathrm{n}(\%)$ & $\begin{array}{c}+ \\
\mathrm{n}(\%)\end{array}$ \\
\hline \multicolumn{9}{|l|}{ Tumor size } \\
\hline$<20 \mathrm{~mm}$ & $133(65)$ & $71(35)$ & $115(60)$ & $76(40)$ & $93(51)$ & 89 (49) & $108(56)$ & $86(44)$ \\
\hline$\geq 20 \mathrm{~mm}$ & $36(49)$ & $37(51)$ & $31(43)$ & $41(57)$ & $34(53)$ & $30(47)$ & $43(66)$ & $22(34)$ \\
\hline & & $\mathrm{P}=0.017$ & & $\mathrm{P}=0.013$ & & $\mathrm{P}=0.78$ & & $\mathrm{P}=0.14$ \\
\hline \multicolumn{9}{|l|}{ ER status ${ }^{\mathrm{a}}$} \\
\hline $\mathrm{ER}^{-}$ & $30(54)$ & $26(46)$ & $23(44)$ & $29(56)$ & $23(47)$ & $26(53)$ & $33(62)$ & $20(38)$ \\
\hline $\mathrm{ER}^{+}$ & $119(62)$ & $74(38)$ & $106(57)$ & $80(43)$ & $87(50)$ & $87(50)$ & $102(57)$ & 77 (43) \\
\hline & & $\mathrm{P}=0.28$ & & $\mathrm{P}=0.10$ & & $\mathrm{P}=0.70$ & & $\mathrm{P}=0.49$ \\
\hline \multicolumn{9}{|l|}{ Tamoxifen } \\
\hline No & $80(57)$ & $60(43)$ & $72(54)$ & $62(46)$ & $64(52)$ & $60(48)$ & $73(57)$ & $56(43)$ \\
\hline Yes & $95(66)$ & $49(34)$ & $78(57)$ & $58(43)$ & $68(53)$ & $61(47)$ & $82(60)$ & $54(40)$ \\
\hline & & $\mathrm{P}=0.13$ & & $\mathrm{P}=0.55$ & & $\mathrm{P}=0.86$ & & $\mathrm{P}=0.59$ \\
\hline
\end{tabular}

${ }^{\mathrm{a}} \mathrm{ER}^{+}, \geq 0.05 \mathrm{fmol} / \mu \mathrm{g}$ DNA.

Table III. Univariate analysis of distant recurrence and breast cancer related mortality rate in relation to COX-2, aromatase, 17HSD1 and 17HSD2 among ER positive patients (RR, rate ratio).

\begin{tabular}{|c|c|c|c|c|c|}
\hline & \multirow[b]{2}{*}{$\begin{array}{l}\text { No. of } \\
\text { patients }\end{array}$} & \multicolumn{2}{|c|}{$\begin{array}{c}\text { Distant } \\
\text { recurrence }\end{array}$} & \multicolumn{2}{|c|}{$\begin{array}{l}\text { Breast cancer } \\
\text { death }\end{array}$} \\
\hline & & $\mathrm{RR}$ & Significance & $\mathrm{RR}$ & Significance \\
\hline \multicolumn{6}{|c|}{ COX-2 } \\
\hline- & 119 & 1.0 & & 1.0 & \\
\hline+ & 74 & 1.66 & $\mathrm{P}=0.13$ & 1.20 & $\mathrm{P}=0.63$ \\
\hline \multicolumn{6}{|c|}{ Aromatase } \\
\hline- & 106 & 1.0 & & 1.0 & \\
\hline+ & 80 & 1.43 & $\mathrm{P}=0.28$ & 0.95 & $\mathrm{P}=0.90$ \\
\hline \multicolumn{6}{|c|}{ 17HSD1 } \\
\hline- & 87 & 1.0 & & 1.0 & \\
\hline+ & 87 & 0.89 & $\mathrm{P}=0.73$ & 0.92 & $\mathrm{P}=0.83$ \\
\hline \multicolumn{6}{|c|}{ 17HSD2 } \\
\hline- & 102 & 1.0 & & 1.0 & \\
\hline+ & 77 & 0.48 & $\mathrm{P}=0.061$ & 0.31 & $\mathrm{P}=0.02$ \\
\hline
\end{tabular}

are important in breast cancer, a correlation between COX-2 and aromatase activity might be expected. Hovewer, cytokines such as IL-6 and TNFa have also been detected to increase aromatase and 17HSD1 activity (20). Miyoshi et al (21) have shown that intratumoral aromatase mRNA levels significantly decrease after chemotherapy, suggesting that antitumor activity of chemotherapy is mediated, at least in part, through suppres-
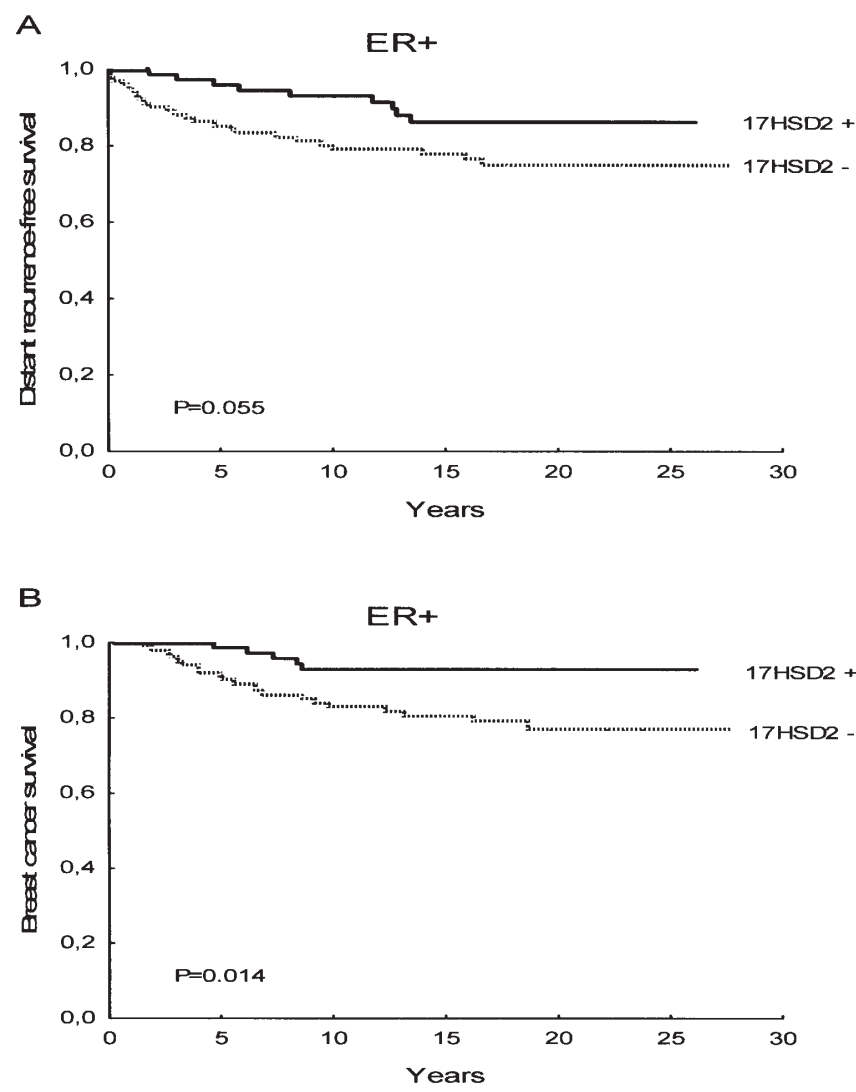

Figure 2. Distant recurrence-free survival (A) and breast cancer survival (B) among estrogen receptor positive patients with decreased and high protein expression of 17HSD2 ( $\mathrm{n}=102$ and $\mathrm{n}=77$, respectively).

sion of intratumoral E2 synthesis. They further suggest that aromatase levels are regulated predominantly by $\mathrm{TNF} \alpha$ and not by IL-6 or COX-2. 
Table IV. Multivariate analysis of distant recurrence and breast cancer related mortality rate among ER positive patients in relation to $17 \mathrm{HSD} 2$ and other variables (RR, rate ratio).

\begin{tabular}{ccc}
\hline & Distant & Breast cancer \\
recurrence & related death \\
No. of & RR Significance & RR Significance \\
patients
\end{tabular}

$\begin{array}{lrrrll}17 \text { HSD2 } & & & & & \\ - & 101 & 1.0 & & 1.0 & \\ + & 76 & 0.5 & \mathrm{P}=0.078 & 0.33 & \mathrm{P}=0.027\end{array}$

Tamoxifen

$\begin{array}{llllll}\text { No } & 80 & 1.0 & & 1.0 & \\ \text { Yes } & 97 & 0.39 & \mathrm{P}=0.010 & 0.35 & \mathrm{P}=0.013\end{array}$

Tumor size

$\begin{array}{lrrrrr}\leq 20 \mathrm{~mm} & 140 & 1.0 & & 1.0 & \\ 21-30 \mathrm{~mm} & 37 & 2.4 & \mathrm{P}=0.019 & 2.9 & \mathrm{P}=0.0077\end{array}$

Aromatase, 17HSD1 and 17HSD2 are involved in the local regulation of estrogen (E1) and estradiol (E2). It has previously been shown that in the normal breast tissue the oxidative pathway $(\mathrm{E} 2 \rightarrow \mathrm{E} 1)$ dominates, whereas in malignant breast tumors the reductive pathway $(\mathrm{E} 1 \rightarrow \mathrm{E} 2)$ is dominant (22). In the present study there was a significant correlation between COX-2 and 17HSD1 and between COX-2 and 17HSD2. This has not previously been described and one possible explanation to this result may be that enzymes involved in estrogen synthesis are simultaneously upregulated. Sasano et al (23) found a significant correlation between 17HSD1 and aromatase among invasive lobular breast carcinomas. In the present study we confirm the correlation between these enzymes in breast tumors.

Surprisingly, 17HSD2 showed positive correlation with all of the other enzymes (Table I). However, this may not necessarily reflect that all of the enzymes are coregulated. Concidering alternative mechanisms behind increased estradiol levels, it might as well reflect a pattern with 17HSD2 positive tumors that more likely might be overexpressing aromatase and 17HSD1, and 17HSD2 negative tumors with normal aromatase and 17HSD1 levels.

In a recent study Oduwole et al (24) described that patients with breast tumors expressing high levels of 17HSD1 mRNA had shorter disease-free and overall survival, and they suggest 17HSD1 as an independent prognostic marker regardless of ER status. Principally in line with their results we found that high levels of 17HSD1 or low levels of 17HSD2 predict recurrence among ER positive patients $(17,18)$. We have previously detected amplification of the gene coding for 17HSD1 in breast cancer, and among ER positive, tamoxifen treated patients, this was associated with decreased breast cancer survival (25). In the present study however, we were not able to detect a prognostic value of 17HSD1.

COX-2 has been described as a marker in breast cancer for more aggressive and less differentiated tumors. Ristimäki et al (8) analyzed the COX-2 protein expression in 1567 invasive breast cancers with immunohistochemistry. Elevated expression of COX-2 was observed in about $40 \%$ of the breast tumors, and was significantly associated with decreased distant recurrence free survival, negative hormone receptor status, high proliferation grade and high p53 expression. O'Connor et al (26) showed that COX-2 expression correlated with treatment failure and diminished survival among women who underwent mastectomy and chest wall radiotherapy. They also found that the level of COX-2 expression was higher among younger patients with invasive breast cancer. On the contrary, Kelly et al (27) described a lack of prognostic effect of COX-2 in primary breast cancer on short-term follow-up. In the present study we did not find any significant difference in prognosis among COX-2 positive or negative patients. However, all patients in our study were postmenopausal and lymph node negative.

In the present study there was a significant difference in prognosis in relation to protein expression of 17HSD2 among ER positive patients. Patients who had a low or undetectable protein expression of 17HSD2 had a significantly higher risk of breast cancer related death. This strongly supports our previous findings, that low levels of 17HSD2 mRNA were associated with a poor prognosis $(17,18)$. It has been suggested that 17HSD1 plays a more important role in breast cancer than 17HSD2 $(23,24)$. However, the relative importance of these enzymes may depend on tumor stage, and as mentioned before the patients in the present study were all lymph node negative. The loss of 17HSD2 expression could result in a significant increase of the more biologically active E2. The gene encoding 17HSD2 is located at 16q24 and loss of heterozygosity ( $\mathrm{LOH})$ at this site is a frequent and early event in breast cancer (28). Moreover, in prostate cancer LOH at 16q is common, and Elo and colleagues (29) discussed whether activity of 17HSD2 protects prostatic epithelial cells from excessive androgen action and reduces the proliferative pressure on prostatic cells. Significantly decreased mRNA expression of 17HSD2 in prostate cancer as compared to normal prostate tissue has also been reported (30).

Adjuvant tamoxifen therapy significantly improves the survival of ER positive breast cancer patients. Recent clinical trials have shown that the recurrence-free survival is further increased with the use of aromatase inhibitor, but biological markers for selecting patients for different kind of endocrine treatment remain to be established. We hypothesize that the expression levels of steroid converting enzymes might predict the efficiency of these treatments.

We found that COX-2 was correlated to the expression of enzymes involved in estrogen synthesis. As earlier mentioned, COX-2 is supposed to upregulate aromatase through PGE2 and cAMP. Furthermore, it has been described that 17HSD1 is upregulated by cAMP in rat granulosa cells (31). If this is true in breast epithelial cells, COX-2 could in part be responsible for the high levels of E2 in breast cancer tissue, through upregulation of both aromatase and 17HSD1. In the normal breast, 17HSD2 will inactivate E2 to the less potent E1, but in the malignant cells, the regulatory function of 17HSD2 might be lost. In the present study we show that patients with low or non-detectable levels of 17HSD2 had a significantly worse prognosis than had patients with normal levels of the enzyme. 


\section{Acknowledgements}

This study was supported by grants from the Swedish Cancer Society. We are grateful to Professor Van Luu-The and Professor Fernand Labrie (Laval University, Quebec, Canada) for kindly providing us with antibodies for the immunohistochemical studies of 17HSD1 and 17HSD2.

\section{References}

1. Sano H, Kawahito Y, Wilder RL, et al: Expression of cyclooxygenase-1 and -2 in human colorectal cancer. Cancer Res 55: 3785-3789, 1995.

2. Wolff H, Saukkonen K, Anttilla S, et al: Expression of cyclooxygenase-2 in human lung carcinoma. Cancer Res 58: 4997-5001, 1998.

3. Yoshimura R, Sano H, Masuda C, et al: Expression of cyclooxygenase-2 in prostate carcinoma. Cancer 89: 589-596, 2000.

4. Tucker O, Dannenberg A, Yang E, et al: Cyclooxygenase-2 expression is up-regulated in human pancreatic cancer. Cancer Res 59: 987-990, 1999.

5. Hwang D, Scollard D, Byrne J, et al: Expression of Cyclooxygenase-1 and Cyclooxygenase-2 in human breast cancer. J Natl Cancer Inst 90: 455-460, 1998.

6. Soslow RA, Dannenberg AJ, Rush D, et al: COX-2 is expressed in human pulmonary, colonic and mammary tumors. Cancer 15 : 2637-2645, 2000.

7. Kirkpatrick K, Ogunkolade W, Elkak A, et al: The mRNA expression of cyclo-oxygenase-2 (COX-2) and vascular endothelial growth factor (VEGF) in human breast cancer. Curr Med Res Opin 18: 237-241, 2002.

8. Ristimäki A, Sivula A, Lundin J, et al: Prognostic significance of elevated cyclooxygenase- 2 expression in breast cancer. Cancer Res 62: 632-635, 2002.

9. Wülfing P, Diallo R, Müller C, et al: Analysis of cyclooxygenase- 2 expression in human breast cancer: high throughput tissue microarray analysis. J Cancer Res Clin Oncol 129: 375-382, 2003.

10. Half E, Ming Tang X, Gwyn K, et al: Cyclooxygenase-2 expression in human breast cancers and adjacent ductal carcinoma in situ. Cancer Res 62: 1676-1681, 2002.

11. Brodie AMH, Lu Q, Fulton A, et al: Aromatase and COX-2 expression in human breast cancers. J Steroid Biochem Mol Biol 79: 41-47, 2001.

12. Brueggemeier RW, Richards JA and Petrel TA: Aromatase and cyclooxygenases: enzymes in breast cancer. J Steroid Biochem Mol Biol 86: 501-507, 2003.

13. Yue W, Wang J, Hamilton C, et al: In situ aromatization enhances breast tumor estradiol levels and cellular proliferation. Cancer Res 58: 927-932, 1998.

14. Vihko P, Isomaa V, Ghosh D, et al: Structure and function of 17ß-hydroxysteroid dehydrogenase type 1 and 2. Mol Cell Endocrinol 171: 71-76, 2001.

15. Peltoketo H, Luu-The V, Simard J, et al: 17beta-hydroxysteroid dehydrogenase (HSD)/17-ketosteroid reductase (KSR) family; nomenclature and main characteristics of the $17 \mathrm{HSD} / \mathrm{KSR}$ enzymes. J Mol Endocrinol 23: 1-11, 1999.
16. Miettinen M, Mustonen M, Poutanen M, et al: 17ß-hydroxysteroid dehydrogenases in normal human mammary epithelial cells and breast tissue. Breast Cancer Res Treat 57: 175-182, 1999.

17. Gunnarsson C, Olsson B and Stål O: Abnormal expression of 17ß-hydroxysteroid dehydrogenases in breast cancer predicts late recurrence. Cancer Res 61: 8448-8451, 2001.

18. Gunnarsson C, Hellqvist E and Stål O: 17ß-hydroxysteroid dehydrogenases involved in local oestrogen synthesis have prognostic significance in breast cancer. Br J Cancer 92: 547-552, 2005.

19. Zhao Y, Agarwal VR, Mendelson CR, et al: Estrogen biosynthesis proximal to a breast tumor is stimulated by PGE2 via cyclic AMP, leading to activation of promoter II of the CYP19 (aromatase) gene. Endocrinology 137: 5739-5742, 1996.

20. Purohit A, Newman S and Reed M: The role of cytokines in regulating estrogen synthesis: implications for the etiology of breast cancer. Breast Cancer Res 4: 65-69, 2002.

21. Miyoshi Y, Kim-Jin S, Akazawa K, et al: Down-regulation of intratumoral Aromatase messsenger RNA levels by Docetaxel in human breast cancers. Clin Cancer Res 10: 8163-8169, 2004.

22. Speirs V, Walton DS, Hall M-C, et al: In vivo and in vitro expression of steroiod-converting enzymes in human breast tumours: associations with interleukin-6. Br J Cancer 81: 690-695, 1999.

23. Sasano H, Frost A, Saitoh R, et al: Aromatase and 17ßhydroxysteroid dehydrogenase type 1 in human breast carcinoma. J Clin Endocrinol Metab 81: 4042-4046, 1996.

24. Oduwole O, Li Y, Isomaa V, et al: 17ß-hydroxysteroid dehydrogenase type 1 is an independent prognostic marker in breast cancer. Cancer Res 64: 7604-7609, 2004.

25. Gunnarsson C, Ahnström M, Kirschner K, et al: Amplification of HSD17B1 and ERBB2 in primary breast cancer. Oncogene 22: 34-40, 2003.

26. O'Connor J, Avent J, Lee J, et al: Cyclooxygenase -2 expression correlates with diminished survival in invasive breast cancer treated with mastectomy and radiotherapy. Int J Radiat Oncol Biol Phys 58: 1034-1040, 2004.

27. Kelly LM, Hill ADK, Kennedy S, et al: Lack of prognostic effect of Cox-2 expression in primary breast cancer on shortterm follow-up. Eur J Surg Oncol 29: 707-710, 2003.

28. Cleton-Jansen AM, Callen DF, Seshadri R, et al: Loss of heterozygosity mapping at chromosome arm 16q in 712 breast tumours reveals factors that influence delineation of candidate regions. Cancer Res 61: 1171-1177, 2001.

29. Elo JP, Harkonen P, Kyllonen AP, et al: Loss of heterozygosity at 16q24.1-q24.2 is significantly associated with metastatic and aggressive behavior of prostate cancer. Cancer Res 57: 3356-3359, 1997.

30. Koh E, Noda T, Kanaya J, et al: Differential expression of 17ßhydroxysteroid dehydrogenase isozyme genes in prostate cancer and noncancer tissue. Prostate 53: 154-159, 2002.

31. Kaminski T, Akinola L, Poutanen M, et al: Growth factors and phorbol-12-myristate-13-acetate modulate the folliclestimulating hormone- and cyclic adenosine-3',5'-monophosphate dependent regulation of 17ß-hydroxysteroid dehydrogenase 1 expression in rat granulosa cells. Mol Cell Endocrinol 136: 4756, 1997. 